\title{
IMPLICACIONES DE LA CONSTITUCIONALIZACIÓN DEL DERECHO PENAL EN LA DOGMATICA PENAL COLOMBIANA. APLICABLE AL TIPO PENAL DE FALSEDAD EN DOCUMENTO PÚBLICO.
}

Implications of the constitutionalization of criminal law in the Colombian criminal dogmatic. applicable to the criminal type of forgery of public document.

$\underline{\text { Ángel Mattos Arévalo }}^{3}$

Fecha de recepción: 31 de octubre de 2017

Fecha de aceptación: 4 de diciembre de 2017

SUMARIO: 1. Introducción; 2. I Supremacía de la constitución: su valor vinculante; 3. II La constitucionalización, fundamentada en las corrientes del denominado neoconstitucionalismo europeo; 4. III La constitucionalización del ordenamiento jurídico colombiano; 5. IV La constitucionalización del derecho en la dogmática penal; 6. V Criterios para el análisis dogmático, con especial atención en falsedad en documento público; 7. VI análisis dogmático de falsedad en documento público; 8. VII Valoración del análisis dogmático de falsedad en documento público; 9. VIII Aplicabilidad de la dogmática reinterpretada por la corte constitucional sobre todo en la relacionada con falsedad en documento público; 10. Conclusiones; 11. Bibliografía

\footnotetext{
${ }^{3}$ Abogado, especialista en Ciencias Penales y Criminológicas de la Universidad de Cartagena, Magister en Derecho de la Universidad de Cartagena. Fiscal delegado ante los Jueces Penales del Circuito en la ciudad de Cartagena. https://orcid.org/0000-0001-66201735 E-mail: angelmattos2@gmail.com
} 


\section{COMO SE CITA ESTE ARTÍCULO (APA 6)}

MATTOS, Ángel (2018). Implicaciones de la constitucionalización del Derecho Penal en la dogmática penal colombiana. Aplicable al tipo penal de falsedad en documento público. Revista Jurídica Mario Alario D’Filippo, Vol. X №. 19X (18), pág. 48-66

\section{RESUMEN}

El constitucionalismo desde la expedición de la Carta política de 1991 ha sido revolucionario, porque se ha otorgado el valor de norma de normas, en su artículo 4. Esto significa que tiene eficacia directa, cuyo cumplimiento es obligatorio y debe ser acorde con el ordenamiento jurídico: incluyendo el derecho penal.

Este artículo tiene el propósito de analizar, las implicaciones del nuevo constitucionalismo desde la dogmática penal, demostrando la influencia de la constitucionalización en la modificación de tipos penales que tradicionalmente en ordenamiento jurídico colombiano tenían un análisis dogmático distinto, entre ellos el análisis del tipo penal Falsedad en documento público.

\section{Palabras Claves}

Constitucionalización, Derecho Penal, Dogmática penal, Análisis dogmático, Falsedad en Documento.

\section{ABSTRACT}

The constitutionalisation since the issuance of the 1991 Political Charter has been revolutionary, because it has been granted the value of norm of norms, in its article 4, this means that it has direct efficacy, whose compliance is mandatory and must be in accordance with the legal system: including criminal law.

This article has the purpose to analyze, the implications of the new constitutionalism from criminal dogmatics, showing the influence that the constitutionalisation has been in modification of criminal type that traditionally in Colombian Legal System had a different dogmatic analysis, one of them, the analysis of the criminal type forgery of public document.

\section{Keywords}

Constitutionalisation, Criminal Law, Criminal Dogmatic, Dogmatic Analysis, forgery of document. 


\section{INTRODUCCIÓN.}

En general el presente artículo de investigación de enfoque cualitativo, jurídico, de tipo analíticodescriptivo, tiene como objetivo general analizar la forma de manifestarse la constitucionalización del derecho penal en la estructuración de la dogmática penal en Colombia, especialmente teniendo en cuenta el análisis del tipo: Falsedad en Documento Público. Lo anterior se realizará: Determinando la influencia de la Constitucionalización en el Derecho Penal Colombiano y los tipos penales que han sido redefinidos a partir de la reinterpretación adecuada a los principios constitucionales, y finalmente evaluando la estructuración actual de la dogmática penal en forma concreta con Falsedad en Documento. La presente investigación se justifica en que se procura extraer los tipos penales que a raíz de la constitucionalización se han reinterpretado, teniendo impacto en el estudio y adecuación de dogmática penal a la carta magna, principalmente el tipo penal relacionado con Falsedad en documento público. resultando innovador y útil para comunidad académica y para los hacen ejercicio profesional del derecho porque les proporciona herramientas para utilizar los planteamientos teóricos de la dogmática penal pero constitucionalizado.

\section{Supremacía de la Constitución: su valor vinculante.}

En general es necesario destacar el sustento teórico que fundamenta la importancia de la Constitución como norma de norma: la supremacía constitucional. De tal manera que la única ley que legal, ideológica y políticamente puede denominarse suprema, es la constitución, en virtud de ello toda norma jurídica secundaria tendrá validez dentro de nuestro sistema legal únicamente si soy posiciones son acordes a los principios establecidos en la Constitución (Sachica, 1984). La Constitución es considerada suprema por los valores y principios fundamentales que alberga, por esta razón es que debe contener una fuerza normativa lo suficientemente eficaz que permita el funcionamiento estructural del sistema jurídico y, de esta manera, no existan elementos que se antepongan a ella (Del Rosario, 2011)

La constitución de 1991, se consagró en su primer artículo como un estado social de derecho, esa autoproclamación será en núcleo esencial por medio del cual la constitución marca el tránsito del Estado de derecho legal al Estado de derecho constitucional, o mejor, en opinión de Ferrajoli, el paso del Estado de Derecho "débil" al estado de Derecho "fuerte". Los jueces, a partir de esta constitución, ya no estarán limitados a ser "la boca inanimada de la ley", sino que, se les reclamara que asuman la Constitución. En el Estado social de derecho se acentúa de manera dramática el problema de la necesidad de adaptar, corregir, acondicionar la aplicación de las normas por medio de la intervención del juez (Arrubla Paucar, 2010). Y además esa nueva autoproclamación soportaría la justificación de una jurisdicción constitucional encargada de un control constitucional, prevalentemente concentrado donde se institucionalizó por medio de la creación de la Corte Constitucional Colombiana. 
En el Estado Social y Democrático de Derecho el Control de Constitucionalidad de las leyes no puede limitarse a la forma, sino que debe apelar al examen de los valores materiales establecidos por la Constitución, sin necesidad de que estos se expresen en un precepto, sino que pueden ser determinados a través de una interpretación del sentido total de la Constitución (Bastidas Mora, 2009). Estas tareas desarrolladas por la Corte Constitucional se han efectuado especialmente en dos líneas diferentes: bien sea actuando en sus competencias de control de constitucionalidad de las leyes o por vía de revisión de tutela (Suárez-Manrique, 2014). La Corte es una institución singularmente comprometida con el ideal del Estado Social de Derecho, por lo que en su jurisprudencia ha estructurado los derechos fundamentales de forma que se preserven los derechos liberales, pero se extienda la protección a los derechos sociales dentro de una economía libre pero solidaria de mercado. Sin duda, en el paradigma neoconstitucional, el juez se vuelve el factor principal en la ecuación jurídica, pues son los mecanismos jurisdiccionales los encargados de garantizar los postulados constitucionales (García Jaramillo, 2008).

\section{La constitucionalización, fundamentada en las corrientes del denominado neoconstitucionalismo europeo.}

La supremacía de la Constitución otorgó fuerza normativa a todo el articulado de la misma, incluyendo la instauración del Estado Social de derecho, que posibilitó la creación institucional de la Corte Constitucional como asignada para el control constitucional. Pero estas realidades jurídicas revolucionarias a la luz del ordenamiento jurídico colombiano, tienen notoria influencia de los postulados neoconstitucionalista que entre sus consecuencias se replanteó el sistema de fuentes del derecho. Aunque el fenómeno de la constitucionalización del derecho no es nuevo en el derecho comparado; en nuestro país comenzó a gestarse a partir de la Constitución Política de 1991 con la creación de la Corte Constitucional. Para el siglo XIX el orden jurídico giraba en torno al acatamiento ciego de la ley; pero a partir del siglo XX las cosas han cambiado porque el eje central lo constituye la Carta Magna o carta fundamental (Arrieta, 2009) La defensa de la Constitución está integrada por todas aquellas instituciones jurídicas sustantivas y procesales que se han establecido en las propias cartas fundamentales tanto para conservar la normativa constitucional como para prevenir su violación reprimir su desconocimiento lo más importante alcanzar el desarrollo y evolución (Fix-Zamudio, 1993). En esta nueva corriente, de la que el ordenamiento jurídico colombiano se fundamentaría para cumplir sus expectativas y fines del estado se caracteriza por según (Vigo, 2007) y (Cortés Zambrano, 2011):

a) El derecho deja de ser un conjunto sistemático de normas para comprender valores y principios, que se encuentran disponibles para las respuestas jurídicas que deben dar los jueces. b) El derecho se judicializa, en cierta medida, superando la distinción entre la creación y la aplicación 
c) El examen de la validez de las normas, incluidas las legales, se amplía a los contenidos constitucionales, que potencian al papel del poder judicial de tal manera que la ley solo tiene validez cuando se encuentre ajustada a la Constitución, toda ley debe ser constitucional.

d) Se habla de la transversalidad del Derecho Constitucional, la ley se ajusta al contenido de los derechos fundamentales, sus contenidos irradian sus efectos a las leyes civiles.

La teoría constitucional moderno neoconstitucionalismo pugna entre otras cosas por una omnipresencia de la constitución en todas las áreas jurídicas y en todos los conflictos mínimamente relevantes (Carbonell, Constitución reforma constitucional y fuentes del Derecho, 2001) proponiendo de esta manera una visión renovada del constitucionalismo trastoque las fuentes del proceso y del Derecho, pues la Constitución no sólo distribuye formalmente el poder sino que, además, condiciona la validez de las normas inferiores que configuran la legislación, la administración y la jurisdicción. La jerarquía Institucional se ha desplazado desde la instancia parlamentaria hasta los Tribunales Constitucionales. Se impone al operador jurídico, interpretar la ley conforme a los valores, principios y preceptivas constitucionales (Bastidas Mora, 2009). Esto es lo que se ha definido como el neoconstitucionalismo, como una nueva teoría del derecho encargada de respaldar el proceso de constitucionalización del derecho vigente, lo cual deja rezagado el iuspositivimo o estado débil del derecho, que servía de sostén al viejo sistema, anclado en la concepción liberal de la sociedad decimonónica (Arrubla Paucar, 2010).

\section{La constitucionalización del ordenamiento jurídico colombiano.}

Estos postulados del neoconstitucionalismo irrigarían en todo el ordenamiento jurídico colombiano, incluyendo las ramas del derecho, de tal manera que desencadenaría el fenómeno jurídico de la constitucionalización. La misma se concebiría como una entidad dinámica en contraposición a una entidad estática; no puede decirse simplemente que un ordenamiento jurídico está o no constitucionalizado, un ordenamiento jurídico puede constitucionalizarse en diferentes grados (Suárez-Manrique, 2014) La constitucionalización del derecho se refiere al fenómeno jurídico según el cual "el ordenamiento jurídico de un país y por tanto el derecho en sí mismo considerado, debe estar regido en su interpretación y aplicación con la Constitución de dicho país. Ello quiere decir que la norma primaria a la cual debe acompasarse en forma obligatoria el derecho del país respectivo debe ser la Constitución" (Dueñas, 2008). La constitucionalización del derecho es un tema de interés universal enriquecido por la Jurisprudencia de los Tribunales Constitucionales de los diferentes países que consideran el texto constitucional con fuerza vinculante y obligatorio marcando el norte que deben seguir las demás leyes, decretos, acuerdos, reglamentos, etc.; realidad a la que no sido ajena Colombia en donde la constitucionalización del derecho es una realidad innegable (Arrieta, 2009). La idea de este fenómeno, es llegar a consolidarse como constitucionalizado, es decir que se encuentre impregnado por las normas constitucionales. Donde la Constitución sea extremadamente 
invasora entrometida capaz de condicionar la legislación jurisprudencia actores políticos y relaciones sociales las condiciones que debe reunir un elemento jurídico para considerar está que está constitucionalizado son las siguientes Constitución rígida garantía jurisdiccional de la Constitución fuerza vinculante de la Constitución sobre interpretación de la Constitución la aplicación directa de Norma constitucional la interpretación conforme de las leyes la influencia de la constitución en las relaciones políticas (Carbonell, Neoconstitucionalismo, 2003).

Lo planteado anteriormente es aspiracional, es el objetivo que se busca en el ordenamiento jurídico. sin embargo, tiene que entenderse que como proceso se hace necesario ciertas condiciones de revisión y estudio. Este proceso de constitucionalización puede revisarse desde una perspectiva descriptiva o prescriptiva. Desde una perspectiva descriptiva, se trata de decir, simplemente, cómo se ha dado el proceso, de dar cuenta de una realidad jurídica tal como se cree que ha venido sucediendo. Responde a la pregunta ¿cómo se ha dado el proceso de constitucionalización del derecho?, Los vehículos más importantes por los cuales se han constitucionalizado los ordenamientos jurídicos son el judicial o el legislativo. La constitucionalización del derecho en el ordenamiento jurídico colombiano ha tenido como principal actor a la Corte Constitucional. Ella ha actuado como principal factor de cambio, defendido y expandido los contenidos de la Constitución en diversas líneas (Suárez-Manrique, 2014). Desde esa óptica se fundamenta el estudio descriptivo de la constitucionalización del derecho penal, teniendo como base a la dogmática penal. Y es a partir de la forma en que se materializa la constitucionalización en el derecho penal, que se estudia la forma en que se concreta en el tipo falsedad en documento público.

\section{La constitucionalización del derecho en la dogmática penal.}

Como se planteó precedentemente en razón del proceso de constitucionalización se hace casi obligatorio un llamado a reflexionar sobre la importancia de la constitucionalización del derecho, especialmente en materia penal porque al establecer la carta magna que "la Constitución es norma de normas"; quiere decir que todo el ordenamiento nacional y aun el supranacional para que cobre vigencia y eficacia debe estar ajustado a la Constitución Política o carta fundamental de Colombia, no siendo ajena dicha influencia al campo del derecho penal y procedimental penal, tema que desde el punto de vista de la doctrina y la jurisprudencia se tratará en la presente investigación (Arrieta, 2009).

En Colombia, la "constitucionalización del derecho" se extiende a todas las ramas del derecho con la expedición de la Constitución política de 1991. Si la Carta Política es norma de norma (artículo 4), creemos que todo el derecho y en especial el derecho penal deben estar supeditado a los preceptos constitucionales (Coba, 2012). "Ha habido una constitucionalización del derecho penal porque tanto en materia sustantiva como procedimental, la Carta incorpora preceptos y enuncia 
valores y postulados - particularmente en el campo de los derechos fundamentales- que inciden de manera significativa en el derecho penal y, a la vez, orientan y determinan su alcance. Esto significa entonces que el Legislador no tiene una discrecionalidad absoluta para definir los tipos delictivos y los procedimientos penales, ya que debe respetar los derechos constitucionales de las personas, que aparecen, así como el fundamento y límite del poder punitivo del Estado. Fundamento, porque el ius puniendi debe estar orientado a hacer efectivos esos derechos $y$ valores constitucionales. Y límite, porque la política criminal del Estado no puede desconocer los derechos y la dignidad de las personas (Sentencia C-038, 1995)".

De esa constitucionalización, surge la importancia de la dogmática penal constitucionalizada que según la (Sentencia C-181., 2016) cumple un papel de innegable trascendencia, pues tiene como finalidad extraer, describir y explicar sistemáticamente el contenido de las normas penales, por lo que a partir de la misma, se analizan aspectos como la tipicidad, antijuridicidad, la culpabilidad, la punibilidad, así como, las teorías, finalidades y valores de la pena, elementos de suma importancia para el estudio de la figura de la reincidencia penal, puesto que el control de constitucionalidad de la Corte, como ya se mencionó, está condicionado por la ubicación en uno de los elementos mencionados. "La tipificación de las conductas punibles, y también consecuentemente de estos nuevos delitos, parte necesariamente del principio de intervención mínima, base del derecho penal, que configura a este como ultima ratio, por tanto, solo puede sancionarse penalmente una conducta cuando las demás normas del ordenamiento jurídico han demostrado ser insuficientes o ineficaces para dispensar la tutela que se pretende, conjugado con el principio de proporcionalidad, entendido como la exigencia de adecuar la sanción penal realmente a la gravedad del hecho tipificado que se ha cometido (Sentencia C-038, 1995)"

Así, en la actualidad el derecho penal se entiende debe estar perfectamente constitucionalizado, es decir, que las normas constitucionales referidas a los derechos fundamentales y obviamente, las que tienen que ver de forma expresa con el derecho penal, entran a jugar como parámetro de evaluación crítica de las normas penales, al mismo tiempo que se constituyen en criterios para su interpretación y aplicación (Cote-Barco, 2008). En su efecto la posición prevalente del art. 9 del código penal colombiano, es consecuencia de una multiplicidad de disposiciones de índole superior que establecen principios limitadores del poder punitivo. Estás disposiciones de carácter superior y vinculante, señaladas en la Carta Magna, revalidan la supremacía de las normas rectoras y edifican unos contornos precisos para su imperativo cumplimiento (Sanchez, 2012).

Incluso desde algunas concepciones de la dogmática penal en la que, por ejemplo, el concepto de acción, cualquiera que se adopte ha de ser consciente del marco sistemático y el conjunto de valores desde el cual se debe construir el derecho penal, es decir, ha de atarse a los límites materiales de la Constitución, los tratados internacionales y los principios de orden intra o 
extrasistémicos que conforman el derecho penal en general. El artículo 9 del Código Penal consagra el denominado concepto dogmático de delito, esto es, un concepto jurídico de delito elaborado a partir del método dogmático (Velásquez V., 2009) así mismo se destaca al derecho penal de acto, se trata de un acto de un hombre (López Morales, 2002 ) Y conceptos como la conducta como presupuesto del delito, y de ella se exige el cumplimiento de tres elementos o categorías: tipicidad, antijuridicidad y culpabilidad, como condiciones previas a la imposición de la pena, así mismo la imputación jurídica introdujo criterios de imputación normativa exigidos por la moderna dogmática (Pabón Parra, 2005) La teoría del nexo causal como fundamento de toda imputación al tipo objetivo, de tal manera que no hay un esquema determinado, sino que es posible "construir un esquema causal, final, funcional" (Fernández Carrasquilla, 2002)

Por lo anterior, la constitucionalización es un paradigma en el derecho, especialmente en el derecho penal donde su normatividad y actuaciones deben estar encausadas en los valores y principios constitucionales, actividades como la interpretación e integración del derecho deben estar acordes a la carta magna pues de esta manera se respeta la dignidad humana y valores superiores.

En forma concreta, el derecho penal se ha constitucionalizado de manera directa cuando algunos tipos penales desde la dogmática penal fueron reinterpretados, permitiendo que se encauzaran de acuerdo con la constitución política. A continuación, se dará mayor ilustración sobre este punto.

En general luego de un análisis exhaustivo de los tipos penales y de la lectura de sentencias de constitucionalidad se encontraron pronunciamientos judiciales en los cuales se hacía revisión de los tipos penales existentes y vigentes en la actualidad, que tiene por objetivo principal evaluar su coherencia con los principios, valores y normas constitucionales. En el proceso de revisión se encontraron 14 sentencias de la Corte Constitucional, que cumplían con la función de reinterpretación, extensión y aclaración de los tipos penales acordes con la constitucionalización en el derecho penal. La muestra fue la siguiente:

\section{Tipo penal}

1. Articulo 104 C. $P^{4}$ Homicidio Agravado, Articulo 170 C.P (Secuestro) el artículo 229 C.P (Violencia Intrafamiliar).

\section{Sentencia de la Corte Constitucional.}

C-029-2007 5 para hacerse extensivo a parejas homosexuales.

4 C.P: se refiere expresamente al código penal.

5 En este mismo sentido se reinterpreto los tipos penales: del articulo 170 C.P y 229 C.P 
Ángel Mattos Arévalo

2. Articulo 104 C.P Feminicidio.

3. Articulo 106 C.P Homicidio por piedad.

4. Articulo 122 C.P Aborto.

5. Articulo 199 C.P Sabotaje.

6. Artículo $229 \quad$ C.P Violencia Intrafamiliar.

7. Articulo 233 C.P Inasistencia Alimentaria

8. Articulo 242 C.P Hurto con circunstancias de atenuación.

9. Articulo 286 C.P Falsedad ideológica en documento público

10. Articulo 305 C.P Usura.

11. Articulo 340 C.P Concierto para delinquir.

12. Articulo 408 C.P Violación del régimen legal o constitucional de inhabilidades e incompatibilidades.

13. Artículo 413 C.P Prevaricato por acción.

14. Articulo 467 C.P Rebelión.
C-297-2016 Estructuración de la Tipicidad.

C-239-1997 Consideraciones especiales acerca de la Eutanasia.

C-355-2006. Circunstancias en la que no hay delito de aborto.

C-858-2008. Distinción entre Huelga, Paro y Huelga Política.

C-368-2014. Concepto de maltrato aplicable al tipo penal.

C-237-1997. Circunstancias de configuración del delito.

C-553-2001. Lo que se entiende por palabra socio.

SU-74-2014. Dolo directo y dolo eventual.

C-479-2001 y T-114-2004. Tipicidad de la Usura y termino de la prescripción.

C-334-2013. Configuración típica.

C-038-1996. Tratamiento para la inhabilidad e incompatibilidad sobreviniente.

C-335-2006 y C-086-2001. Agrega a la tipicidad, el no acatamiento a la jurisprudencia.

C-428-2005. Delito Político.

Luego del resultado anteriormente obtenido de la revisión, a efectos señalados precedentemente se dará prioridad al análisis dogmático del tipo penal relacionado como Falsedad en Documento público, en coherencia con las especificidades y labores de reinterpretación de la Corte Constitucional. Para lo anterior se requiere del estudio dogmático, y los criterios que se tendrán en cuenta para la presente investigación. Con énfasis en: Articulo 286 C.P Falsedad ideológica en documento público. 
Ángel Mattos Arévalo

\section{IV.Criterios para el análisis dogmático, con especial atención en falsedad en documento público.}

Es importante tener en cuenta que el estudio dogmático, se realizará conforme a los criterios que el propio ordenamiento penal establece, bajo los criterios de tipicidad, antijuridicidad y culpabilidad. Es decir, bajo las teorías clásicas de la dogmática penal, de tal manera que lo anterior será insumo para lograr una descripción y abordaje dogmático del tipo penal falsedad en documento público.

Según (Aguas Baldovino \& Tapia Ariza, 2015) la ley 599 del 2000, en lo referente a la tipicidad y la culpabilidad acoge el concepto finalista de la teoría del delito, mientras que en lo que respecta a la antijuridicidad, adopta el concepto funcionalista de ROXIN. En el artículo noveno de esta normatividad se preceptúa que para que la conducta sea punible se requiere que sea típica antijurídica y culpable; elementos que analizaremos así:

Tipicidad. Preceptuado en la ley 599 del 2000, en su artículo 10, Se constituye uno de los pilares del principio de legalidad, lo que genera una relación amplia y dinámica con el derecho fundamental al debido proceso, debido a que es la consagración normativa de los comportamientos humanos reprochables desde el punto de vista penal, a través de esquemas dogmáticos y las pautas de derecho positivo vigentes. Se ha dicho que sin tipicidad no hay delito. También que "el principio de legalidad encuentra su perfecta complementación en el de tipicidad". el tipo se encuentra compuesto por unos elementos normativos (tipo objetivo) y unos elementos subjetivos (tipo subjetivo):

- Tipo objetivo: sujetos (activo y pasivo), objeto, conducta, ingrediente normativo.

- Tipo subjetivo: dolo (dolo directo, dolo indirecto, dolo eventual), culpa (consciente e inconsciente), preterintencional.

Antijuridicidad. según la (Sentencia C-070, 1996) no es un principio con expresa regulación constitucional, sin embargo, esta Corporación ha establecido que guarda una íntima conexión con el principio de proporcionalidad o "prohibición de exceso" el cual se deduce jurisprudencialmente de los postulados de Estado Social de Derecho, la dignidad humana, la efectividad de los principios, derechos y deberes consagrados en la Constitución, los derechos inalienables de la personal, prohibición de la pena de muerte y de tratos o penas crueles, inhumanos o degradantes, el principio de igualdad y de la proporcionalidad de las medidas excepcionales. Según el bien jurídico que tutelan: pueden ser de lesión o peligro, los primeros son los que describen conductas que llevan envuelta la destrucción o el menoscabo de los bienes jurídicos y los segundos describen conductas que no llevan envuelta la destrucción ni el menoscabo del bien jurídico tutelado, pero que contienen una amenaza o un peligro para el tutelados por la norma. 
a) Según su estructura: básico o especial o subordinado, se tiene por tipo básico aquel que se aplica sin sujeción a ningún otro penal porque en ellos se describe automáticamente un comportamiento o conducta; se tiene por tipo especial a que tiene elementos propios además del básico y por ello se aplican con independencia del mismo e igualmente el subordinado es aquel tipo penal que "por relacionarse intrínsecamente con el tipo básico y mostrar hechos que cambian la conducta básica, el objeto o los sujetos, no puede aplicarse sin tener en cuenta el básico".

Asimismo, puede ser autónomo o en blanco, en el cual el autónomo consiste en aquel que describe la conducta en forma total, de tal manera que para comprenderlo no hay necesidad de acudir a la interpretación sistemática o a otros estatutos con el pretexto de complementar su significado; en tanto el tipo en blanco no describe la conducta en forma total, remitiéndose el legislador al mismo texto o a otros ordenamientos jurídicos para que quede completo. En otras palabras, el que contiene un vacío que debe ser llenado por otra norma, para poder hacer la adecuación típica

E igualmente tener en cuenta los elementos normativos, De acuerdo a lo esbozado por (Urbano Martínez, 2011) y (Velazquez, 2003)

a) Sujetos: en la dogmática de cada tipo penal se identifican dos, sujeto activo y sujeto pasivo. El primero es quien desarrolla, en todo en parte, la conducta prohibida por el tipo penal mientras que el segundo es el titular del bien jurídico tutelado (sea una persona individual una colectividad o un ente estatal).

b) Objeto: en la dogmática de cada tipo penal se conoce como todo aquello sobre lo que recae la conducta del sujeto activo. Se distingue el objeto material y el jurídico, el primero se aprecia en concreto el objeto, en tanto el segundo es hace referencia a su abstracción jurídica.

c) Conducta: en la dogmática de cada tipo penal se conoce como toda expresión gramatical de la conducta se hace a través de verbos, que pueden referirse de manera simple al objeto (matar a otro) o de manera compleja, cuando un verbo, por sí mismo, carece de sentido lógico suficiente para delimitar el comportamiento reprochable (inducir en error, acceder carnalmente).

d) Ingredientes normativos: en la dogmática de cada tipo penal se conoce como aquellas expresiones que requieren, para su adecuada compresión, de un juicio valorativo referido a otras normas del ordenamiento jurídico o a un determinado contexto socio cultural o técnico científico.

e) Elemento de tipo subjetivo: se definen como modalidades de la conducta punible; y estas son el dolo, la culpa y la preterintencion. 


\section{Análisis dogmático de falsedad en documento público.}

Los conceptos precedentemente reseñados serán el sustento para adecuar la descripción y estudio dogmático del tipo penal del articulo 286 C.P Falsedad ideológica en documento público ${ }^{6}$. tipo penal cualificado, de lesión, en blanco, compuesto.

\section{a. Sujeto activo: Cualificado.}

b. Objeto jurídico: Contra la fe pública.

c. Objeto material real. Documento.

d. Verbo rector: extender, consignar, callar

e. Ingrediente normativo: en ejercicio de sus funciones, al extender documento público que pueda servir de prueba, consigne una falsedad o calle total o parcialmente la verdad.

Según la Sentencia SU-074-14, La Corte Constitucional en una sentencia de unificación realiza una revisión de un numero plural de sentencias tutelas relacionadas contra sentencias por presunta vulneración del debido proceso en razón principalmente a la indebida valoración de la prueba, sobre todo en las relacionadas con la adecuación típica de falsedad en documento público que permite mayor extensión y comprensión sobre la adecuación de tipo subjetivo. De acuerdo con el artículo 22 del Código Penal, una conducta es dolosa (i) "cuando el agente conoce los hechos constitutivos de la infracción penal y quiere su realización", o (ii) "cuando la realización de la infracción penal ha sido prevista como probable y su no producción se deja librada al azar". El primero de los supuestos, que exige conocimiento y voluntad es conocido como dolo directo, mientras que el segundo suele denominarse dolo eventual. El dolo directo, requiere de la prueba sobre el conocimiento del carácter antijurídico de la conducta, y la voluntad de realizarla. El dolo eventual, la demostración de un conocimiento sobre la probabilidad cierta (así lo expresó la Corte Suprema de Justicia en el caso de la jueza que suscribía declaraciones extra proceso) de incurrir en un hecho ilícito, y la total despreocupación frente a ese resultado probable (consentirlo o dejarlo librado al azar). "No es arbitraria la consideración de la Corte Suprema de Justicia según la cual "puede presumirse que un juez conoce lo que firma" y, en esa medida, salvo la existencia de razones especialmente poderosas, suscribir un documento sin examinar cuidadosamente el contenido es aceptar como probable la ocurrencia del resultado"

De tal manera que según el juicio de:

6 ART. 286. - Falsedad ideológica en documento público. El servidor público que, en ejercicio de sus funciones, al extender documento público que pueda servir de prueba, consigne una falsedad o calle total o parcialmente la verdad 
Ángel Mattos Arévalo

Tipicidad

La Corte realizó una reinterpretación al establecer la aplicabilidad del dolo directo y dolo eventual en este tipo penal, sin dar lugar a confusión entre el dolo eventual y la culpa.

Antijuridicidad

Culpabilidad

\section{VI.Valoración del análisis dogmático de falsedad en documento público.}

Según la sentencia SU-074-14, se constituye conducta típica de falsedad ideológica en documento público cuando se firma información no adecuada con la realidad, así la misma consigne errores en la administración judicial. Pues se trata de un dolo eventual y no de una modalidad culposa (negligencia), debido a que el resultado se deja al azar.

Este tipo de decisión en sede constitucional, favoreció a una interpretación que contraviene los principios del derecho penal que a continuación se precisarán:

a) Derecho penal como ultima ratio. Según la (Sentencia C-365, 2012) el derecho penal se enmarca en el principio de mínima intervención, según el cual, el ejercicio de la facultad sancionatoria criminal debe operar cuando las demás alternativas de control han fallado. El derecho penal debe ser un instrumento de última ratio para garantizar la pacífica convivencia de los asociados, previa evaluación de su gravedad y de acuerdo a las circunstancias sociales, políticas, económicas y culturales imperantes en la sociedad en un momento determinado. En razón a que el error judicial que se materializa en la expedición de documentos de carácter judicial, donde no se visiona como un problema antijurídico que pueda ser atendido por otras ramas del derecho.

En general a partir del pronunciamiento de la corte, el error judicial que consigne falsedad en documento se convierte en una conducta irreprochable desde el punto de vista del derecho penal. No obstante, esta conducta puede reprocharse socialmente desde otros ordenamientos jurídicos como el disciplinario o desde la propia jurisdicción civil. Desde el derecho disciplinario se buscaría la amonestación desde su función como servidor público judicial y desde la jurisdicción civil se buscaría la revocación del acto judicial en cuestión y la indemnización de perjuicios en caso de ser procedente.

b) Principio de legalidad y tipicidad. Según la (Sentencia C-365, 2012) En virtud de los principios de legalidad y tipicidad el legislador se encuentra obligado a establecer claramente en qué circunstancias una conducta resulta punible y ello con el fin de que los destinatarios de la norma sepan a ciencia cierta cuándo responden por las conductas prohibidas por la ley. En base a lo anterior, a pesar de la conducta de falsedad en 
documento público exige conocimiento y voluntad para que se configure como dolosa, se valora el indicio como prueba a través de la consideración de la posición del juez que "debe conocer el documento que firma" y en base a ello decide fallar y considerar como precedente que el error judicial, que tenga por consecuencia la expedición de una providencia judicial que consigne una falsedad alteración de la verdad sea una modalidad conductual punible. Aspecto que a la luz de la interpretación crea una nueva modalidad para establecer dolo eventual en falsedad en documento público.

c) Principio de favorabilidad. Por medio de la cual se aplica la norma más favorable para el procesado penal o reo. En este sentido la norma fue interpretada en sede judicial, siguiendo las corrientes filosóficas de la reinterpretación considera lo siguiente en la interpretación en sentido correctivo: que se considera opuesta a la literal donde consiste en interpretar el derecho literalmente, utiliza otros métodos para la solución del conflicto. A través del cual sea posible conjeturar un significado, en decidir o proponer un significado o en crear un significado(Gimeno, 2000). En la misma es posible la interpretación creativa, que consiste en atribuir a un texto un significado "nuevo" no comprendido entre los significados identificados (o identificables) por medio de la interpretación cognitiva asume una forma ligeramente distinta, consistente en extraer del texto normas no expresas (dichas "implícitas", en un sentido amplio no estrictamente lógico) mediante una amplia variedad de argumentos no deductivos (e.g., a contrariis, a simili, etc.). Dicha operación (la "construcción" de normas no expresas) e igualmente favorece La interpretación decisoria, que consiste en elegir un determinado significado entre los significados identificados (o identificables) por medio de la interpretación cognitiva (Guastini, El escepticismo ante las reglas replanteado, 2012).

De esta manera la Corte Constitucional elaboró y decidió elegir una aplicación normativa que contraviene el sentido de favorabilidad al decidir considerar punible en grado de dolo eventual, el error judicial que tenga por consecuencia la expedición de una providencia judicial que consigne una falsedad o alteración a la verdad sea una modalidad conductual punible, por encima de considerarlo culposo y por tanto Atípico, teniendo en cuenta que el tipo penal Falsedad en documento público no se considera en su modalidad culposa.

\section{Aplicabilidad de la dogmática reinterpretada por la corte constitucional sobre todo en la relacionada con falsedad en documento público.}

El anterior estudio dogmático tiene utilidad y relevancia debido a que el constitucionalismo ha fomentado el activismo judicial mediante jurisprudencia, favoreciendo a que los pronunciamientos de la Corte Constitucional se encarguen además de la reinterpretación de normas, que consolidan una nueva forma de aplicar leyes. 
El derecho penal, no es ajeno al fenómeno del constitucionalismo y sus normas aplicables deben aplicarse de acuerdo a lo instaurado y determinado por la Corte Constitucional. En esta medida resulta relevante hacer el estudio de los tipos penales reinterpretados por el tribunal constitucional colombiano debido a que favorece una aplicación normativa adecuada a la constitución puesto a que implica cambios en su dogmática, concretamente para el caso atiente al estudio dogmático de la reinterpretación de la Corte Constitucional en el Tipo Falsedad en documento público.

a. Sirve a los fiscales para realizar adecuaciones típicas pertinentes o para archivo. Según cada caso determinado, el estudio en abstracto realizado de forma precedente establece parámetros para configurar tipicidad sobre algunos tipos e igualmente causales de exclusión, que de acuerdo a cada contexto permitirán que bien prospere la calificación jurídica de delito en cualquiera de sus instancias procesales o que realice $\operatorname{archivo}^{7} 0$ preclusión ${ }^{8}$ cuando exista causales de exclusión que si bien no están claras en la norma, si en la reinterpretación de la jurisprudencia constitucional.

b. Sirve a los defensores para saber cuándo están ante causales de exclusión según la Corte Constitucional y por estudio dogmático evaluar si la calificación jurídica efectuada por la fiscalía corresponde también con el espíritu de la corte. En general es una herramienta de defensa conocer de mejor manera el estudio dogmático, pues el mismo permitirá ejercer una mejor defensa técnica cuando se presente una causal de exclusión expresamente señala por la Corte Constitucional, sin que expresamente aparezca en la ley y además favorece el análisis comparativo de tipos para diferenciarlos y obtener la calificación correspondiente según el caso.

c. Sirve como referente a los jueces penales. Además de cumplir con el deber de hacer efectiva la supremacía de la constitución mediante la aplicación directa de la jurisprudencia constitucional que reinterpreta los tipos penales en la dogmática, favorece a que sea aplicado un derecho penal contextualizado al derecho vivo y congruente a la verdad procesal.

7 ARTíCULO 79. ARCHIVO DE LAS DILIGENCIAS. Del CODIGO DE PROCEDIMIENTO PENAL. Cuando la Fiscalía tenga conocimiento de un hecho respecto del cual constate que no existen motivos o circunstancias fácticas que permitan su caracterización como delito, o indiquen su posible existencia como tal, dispondrá el archivo de la actuación. Sin embargo, si surgieren nuevos elementos probatorios la indagación se reanudará mientras no se haya extinguido la acción penal.

8 El artículo 332 de la Ley 906 de 2004 señala que el fiscal solicitará la preclusión de la investigación en los siguientes casos:

1. Imposibilidad de iniciar o continuar el ejercicio de la acción penal.

2. Existencia de una causal que excluya la responsabilidad, de acuerdo con el Código Penal.

3. Inexistencia del hecho investigado.

4. Atipicidad del hecho investigado.

5. Ausencia de intervención del imputado en el hecho investigado.

6. Imposibilidad de desvirtuar la presunción de inocencia.

7. Vencimiento del término máximo previsto en el inciso segundo del artículo 294 del este código. 
En general del análisis de estudio dogmático del tipo Falsedad en Documento público, tenemos que posiblemente difícilmente se configure este tipo en modalidad dolosa por dolo eventual, tal como pretende aplicarlo la Corte Constitucional en base a que teniendo en cuenta las externalidades judiciales y los aspectos socio jurídicos de la decisión, es importante tener en cuenta que por la dinámica de la administración judicial que requiere que se proceda con celeridad ante las demandas de congestión judicial. Y a pesar de que se intente ser diligente con las actuaciones judiciales, siempre van a ser susceptibles de errores judiciales.

Además, en realidad jurídica, difícilmente se va a configurar falsedad en documento público en modalidad dolosa eventual pues desde el aspecto probatorio difícilmente se va a poder probar tipicidad mediante la valoración de elementos probatorios constituyentes en indicios y razonamientos lógicos para demostrar el dolo. Que a todas luces resulta inconstitucional, pues debe procederse a la valoración de otros elementos materiales probatorios como testimonios, pruebas documentales entre otros que permitan deducir soportablemente la inferencia razonada. Incluso podría invocarse causal de archivo dentro de la sede de la Fiscalía alegando imposibilidad de desvirtuar la presunción de inocencia

\section{Conclusiones.}

1. La constitucionalización ha impregnado todo el ordenamiento jurídico, influenciado a todas las ramas derecho. es un paradigma en el derecho, especialmente en el derecho penal donde su normatividad y actuaciones deben estar encausadas en los valores y principios constitucionales, actividades como la interpretación e integración del derecho deben estar acordes a la carta magna pues de esta manera se respeta la dignidad humana y valores superiores. De tal forma que la Constitucionalización ha sido influyente y determinante en I manera de estructurar y concebir el derecho penal.

2. De esa constitucionalización, surge la importancia de la dogmática penal constitucionalizada que según la cual cumple un papel de innegable trascendencia, pues tiene como finalidad extraer, describir y explicar sistemáticamente el contenido de las normas penales, por lo que a partir de la misma, se analizan aspectos como la tipicidad, antijuridicidad, la culpabilidad, la punibilidad, así como, las teorías, finalidades y valores de la pena, elementos de suma importancia para el estudio de la figura de la reincidencia penal, puesto que el control de constitucionalidad de la Corte, como ya se mencionó, está condicionado por la ubicación en uno de los elementos mencionados.

3. Las teorías de la dogmática penal y los elementos que lo conforman deben estar constitucionalizados, y para ello se tiene a la jurisprudencia constitucional tiene por objetivo que exista correspondencia entre la ley penal y la constitución, lo que para ello se recurre a la herramienta de la reinterpretación, concretamente redefinir los tipos penales a través de la constitución. 
4. De la revisión de tipos penales reinterpretados se encontraron alrededor de 14, entre los que sobresalen la nueva interpretación al tipo penal Falsedad en documento público, al establecer una nueva modalidad para configurarse dolo eventual, a través del error judicial que consigne una falsedad $u$ omita una verdad.

5. En general, del estudio dogmático reinterpretado del tipo penal falsedad en documento público se deduce que el mismo en lugar de encausarse en los valores y principios de la Constitución política, se separa debido a que vulnera principios penales de carácter constitucional como: el derecho penal como ultima ratio, el principio de legalidad y tipicidad e igualmente el principio de favorabilidad. Además, se concluye que desde la realidad social es difícil la configuración de esa modalidad conductual en el tipo reseñado y así mismo la prueba del mismo, que desde sede de jurisdicción constitucional se sustenta prioritariamente e indicios y deducciones razonables.

\section{REFERENCIAS BIBLIOGRÁFICAS}

AGUAS Baldovino, A. P., \& Tapia Ariza, A. A. (2015). El delito de alteración de resultados electorales, aplicabilidad o inaplicabilidad en el orden jurídico penal colombiano. Cartagena de Indias: Tesis de grado. Universidad de Cartagena.

ARRIETA, V. (2009). La Constitucionalización del Derecho y su incidencia en Colombia. Revista Pensamiento Americano, 65 - 69.

ARRUBLA Paucar, J. A. (2010). La Constitucionalización del Derecho Privado. Revista Nuevo Derecho, 47-73.

BASTIDAS Mora, P. (2009). El modelo constitucional del Estado Social y democrático de derecho, sus desafíos y la constitucionalización del proceso . Via lurus, 45-59.

CARBONELL, M. (2001). Constitución reforma constitucional y fuentes del Derecho . México: Porrúa.

CARBONELL, M. (2003). Neoconstitucionalismo. Madrid: Trota.

COBA, M. (2012). La Constitucionalización del Derecho Penal en Colombia. , . Revista de Derecho de la Universidad Libre de Colombia, Seccional Barranquilla.

CORTÉS Zambrano, S. P. (2011). La Constitucionalización del Derecho y La Interpretación Jurídico Constitucional. Via Inveniendi Et ludicandi. 
COTE-Barco, G. (2008). Constitucionalización del Derecho Penal y Proporcionalidad de la pena. . Vniversitas., 119-151.

DEL ROSARIO, M. F. (2011). La Supremacía Constitucional: Naturaleza y Alcances. Dikaión.

DUEÑAS, O. (2008). Lecciones de Teoría Constitucional. Bogotá D.C: Librería Ediciones del Profesional.

FERNÁNDEZ Carrasquilla, J. (2002). Principios y normas rectoras del derecho penal. Bogotá D.C: Leyer.

FIX-Zamudio, H. (1993). Justicia Constitucional y Derechos Humanos. México : Comisión Nacional de los Derechos Humanos.

GARCÍA Jaramillo, L. (2008). El “Nuevo Derecho” en Colombia: ¿Entelequia Innecesaria o Novedad Pertinente? Revista de Derecho, Universidad del Norte, 289-330.

LÓPEZ Morales, J. (2002 ). Nuevo Código Penal. . Bogotá, D.C.: : Ediciones Doctrina y Ley.

MENDOZA, V. L. (1991). Derecho Penal General. Tercera Edicion. Bogotá D.C: Temis.

PABÓN Parra, P. A. (2005). Comentarios al Nuevo Código Penal sustancial (4̣a ed.). Bogotá D.C: Ediciones Doctrina y Ley.

PARRA, P. A. (2006). Código penal esquemático. Bogotá D.C: Ediciones Doctrina y Ley.

REBOLLO Vargas, R. (2013). Derecho Penal, constitución y derechos. . Barcelona,: Bosch Editor.

SACHICA, L. C. (1984). La Constitución y su defensa. México: Universidad Autonoma de México.

SANCHEZ, S. (2012). La Conducta Punible en el Derecho Penal Colombiano: Análisis del Artículo 9 Del Código Penal. Medellín: Universidad Eafit.

SANTIAGO, A. (2008). Sistema Jurídico, Teoría Del Derecho Y Rol De Los Jueces: Las Novedades Del Neoconstitucionalismo. . Dikaión, 131-155.

SENTENCIA C-038 (Corte Constitucional. 9 de Febrero de 1995). 
Ángel Mattos Arévalo

SENTENCIA C-070 (Corte Constitucional 22 de Febrero de 1996).

SENTENCIA C-181. (Corte Constitucional 13 de Abril de 2016).

SFERRAZZA, P. (2010). La Teoría Jurídica Crítica de Luigi Ferrajoli. Papeles de Teoría y Filosofía del Derecho .

SUÁREZ-Manrique, W. (2014). La constitucionalización del derecho en el ordenamiento jurídico colombiano. Vniversitas, 317-351 .

URBANO Martínez, J. J. (2011). Lecciones de Derecho Penal General. Bogotá D.C: Universidad Externado de Colombia.

VARGAS Vargas, P. P., \& Londoño Herrera, T. (2001). Derecho penal general. En más de mil preguntas con sus respuestas y notas. . Bogotá D.C: Doctrina y Ley Limitada.

VEGA, H. (2016). El análisis gramatical del tipo penal. En Justicia, 53-71.

VELÁSQUEZ V., F. (2009). Manual de Derecho Penal, Parte General . Medellín: Comlibros.

VELAZQUEZ, F. (2003). Manual de Derecho Penal parte General. Bogotá D.C: Ediciones Juridicas Andrés Morales.

VIGO, R. (2007). El neoconstitucionalismo y la función judicial: Límites, Riesgos y perspectivas. Bogotá.

ZAPATA, S. F. (2014). La conducta punible en el Derecho Penal colombiano: análisis del artículo 9 del Código Penal. . Revista de Derecho., 33-64. 